\title{
Extending the service life of Swiss bridges of cultural value
}

Eugen Brühwiler Dr Civil Engineer ETH

Professor of Structural Engineering, Ecole Polytechnique Fédérale de Lausanne (EPFL), Lausanne, Switzerland

Bridges of high cultural value and aesthetic quality deserve respectful treatment and construction interventions must balance these assets with the severe requirements of utilisation. This is particularly relevant to structural engineers and bridge owners involved in rehabilitation or modification interventions. This paper presents, by means of eight bridges in Switzerland, examples of how interventions can be performed with adequate respect to cultural value. It is argued that the preservation of cultural value may go hand in hand with socio-economic, environmental and technical requirements following the principles of sustainable development. These requirements are met through the application of advanced structural engineering methods specific to existing structures. Extending service life not only adds value to bridges - it also leads to an appreciation of the art of structural engineering and the identity of the engineers themselves.

\section{Introduction}

With the exception of structures with recognised historical and technical importance, bridges have yet to find adequate consideration as objects of high cultural value. The intervention of bodies for the preservation of monuments has been limited in the domain of bridges, focusing mainly on riveted steel or masonry bridges built prior to the twentieth century. Only in exceptional cases are bridges from the twentieth century considered as structures of high value. Examples of these in Switzerland include the bridges of the world-famous Swiss engineer Robert Maillart who was active between 1900 and 1940. The determining factor may be that most bridge engineers are not educated to recognise cultural value and aesthetic qualities of such structures and in particular fail to acknowledge them as contemporary monuments.

Consequently, many bridges of high cultural value have already been subjected to interventions based purely on technical criteria without any consideration given to cultural value. Because of this, many of the less well-known, but nevertheless valuable, bridges have been defaced. For example, a bridge's appearance can be disfigured by adding new structural elements, removing or modifying details or erasing structural age indicators, thus damaging the bridge's identity and historical features.

To prevent further loss of cultural value, bridge engineers, owners, preservation authorities and the public need to be encouraged and empowered to give adequate esteem and importance to bridges. This paper presents, by means of examples, how interventions on bridges can be performed with adequate respect to their cultural value. It is argued that the preservation of cultural value may go hand in hand with socioeconomic, environmental and technical requirements following the principles of sustainable development. These requirements can be met by application of advanced structural engineering methods for existing bridges.

\section{Dealing with bridges of high cultural value}

\subsection{Objectives of protection and scope of action}

Bridges are built to serve several generations. As part of the transportation infrastructure, bridges add value to the public economy. Therefore, there is high interest in economic performance while providing unrestricted utilisation (e.g. without limits on traffic loads). Also, the safety of individuals and society needs to be considered in a well-balanced manner according to the bridge's significance within a given transportation system. A bridge is designed for a specific traffic type and its conversion to a different use is questionable.

The continued and contemporary use of a bridge is central and must be guaranteed. This may, however, cause conflict with the conservation of the bridge. While the primary structural elements shall be preserved for the longest possible extent, elements of equipment are subject to wear and require periodic renewal. Their conservation would often make contemporary utilisation impossible and, consequently, elements of shorter 
lifespan such as kerbs or pavement may therefore be adapted or even replaced.

Cultural value is preserved when sustainable development principles are followed. This implies preservation of a bridge's features, substance and appearance as well as its relation to the overall appearance of the location and surrounding landscape. As a consequence, any intervention on a bridge needs to be economical, must respect the environment and resources and be socially and culturally compatible when considering current needs and requirements. The challenge for a structural engineer is to demonstrate that the bridge's real load-carrying capacity is sufficient for modern traffic needs and that only minor interventions are necessary to re-establish and/or improve durability.

\subsection{Structural engineering in the domain of existing structures}

The contemporary approach to existing structures is based on an inherent methodology that essentially includes collecting detailed in situ information about the structure. The controlling parameters are determined more precisely and, for example, the structural safety of an existing bridge can be proved using so-called updated values for actions (loads) and resistance. In this way, it can often be shown that an existing bridge may be subjected to higher load effects while meeting the safety requirements, thereby avoiding intervention.

This methodology has evolved and been successfully applied over the last 20 years. However, it has not yet been fully adopted by many structural engineers, possibly because there are no codes on existing structures available for engineers to rely on. As current codes do not address the major issues of existing structures, their application is fundamentally wrong and often leads to unnecessary interventions. A change of paradigm is needed in the structural engineering community to clearly distinguish between codes for new and existing structures. For this reason, the Swiss Society of Engineers and Architects (SIA) recently released a series of codes for existing structures (Brühwiler et al., 2012).

\subsection{Types of intervention}

There are two basic types of intervention on bridges rehabilitation and modification. The objective of the former is to restore structural safety and serviceability of a bridge for a given service life under constant criteria of functionality and utilisation. The objective of modification, on the other hand, is to transform the functional properties of an existing bridge in response to a foreseen increase of utilisation requirements (e.g. higher traffic loads or a wider driving surface).

Accordingly, the function and utilisation of a bridge determine the type of intervention needed for its preservation. When performing interventions on bridges of high cultural value, the following two questions regarding bridge aesthetics are raised.

- Does the original character - the structural form, structural details and surface colour and texture - need to be preserved?

- Shall the bridge's appearance be intentionally modified by the intervention? In other words, will the intervention be visible?

In principle, the basic concept of an intervention should be evident and understandable. The original character should be preserved in rehabilitation interventions. In modification interventions, however, the appearance of the structure may change according to the needs.

\section{Examples}

The principles outlined in Section 2 are illustrated by the following examples of interventions to extend the service life of bridges of high cultural value in Switzerland.

\subsection{Railway bridge over the Rhine}

Designed by the famous German railway engineer Robert Gerwig (1820-1885) and constructed in 1858, this bridge is the oldest riveted railway bridge still in service in continental Europe (Figure 1). The riveted wrought-iron girder is typical of the nineteenth century railway construction era in central Europe. Accordingly, the bridge's cultural value is obviously high (Brühwiler and Hirt, 2010).

In 1999, the bridge was upgraded for modern railway traffic of the Zurich metropolitan area. To estimate the remaining fatigue life of the bridge structure, a detailed examination was

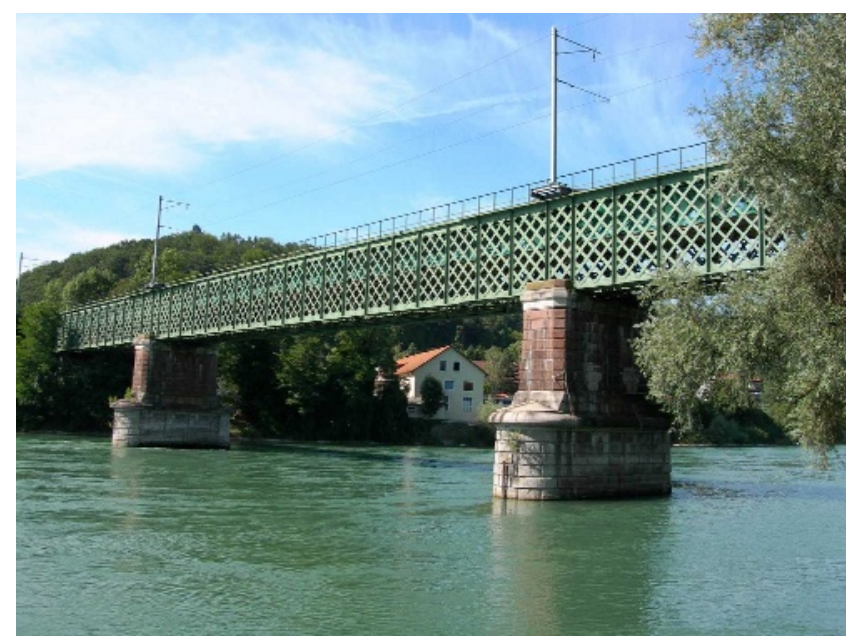

Figure 1. Railway bridge over the Rhine between Waldshut (Germany) and Koblenz (canton of Aargau, Switzerland) 
performed using realistic past and future traffic models as well as advanced knowledge of the fatigue behaviour of riveted wrought-iron details. It was proven that the bridge structure was safe and its service life could be considerably extended for the foreseen passenger train traffic (Keller et al., 1995).

More recently, the bridge was again examined in view of a long remaining service life of 100 years and considering increasing future passenger train traffic. Sufficient fatigue safety and structural safety was again confirmed. To guarantee the bridge's durability over the next 100 years, future rehabilitation works, including replacement of the open railway track (to be performed in 2015), were shown to be by far more cost effective and economical than bridge replacement (an option that was often and is still chosen in such situations).

\subsection{Dorénaz road bridge over the Rhone}

This three-span reinforced concrete (RC) girder bridge (Figure 2), constructed in 1933, was designed by Alexandre Sarrasin (1895-1976), a well-known Swiss engineer who specialised in RC (Brühwiler and Frey, 2002; Habel and Brühwiler, 2009). The simplicity and harmony of forms and the economical use of building materials are among the remarkable characteristics of this bridge design. The structural details of the piers contribute to the bridge aesthetics. This bridge has been recognised as an important landmark of attractive concrete bridges in the initial phase of widespread application of concrete constructions.

Dorénaz Bridge was rehabilitated in 1999 to meet the needs of unrestricted modern road traffic. Detailed examination using updated models of actual structural resistance and traffic actions provided the basis for an intervention limited to invisible strengthening of the deck slab to restore its structural

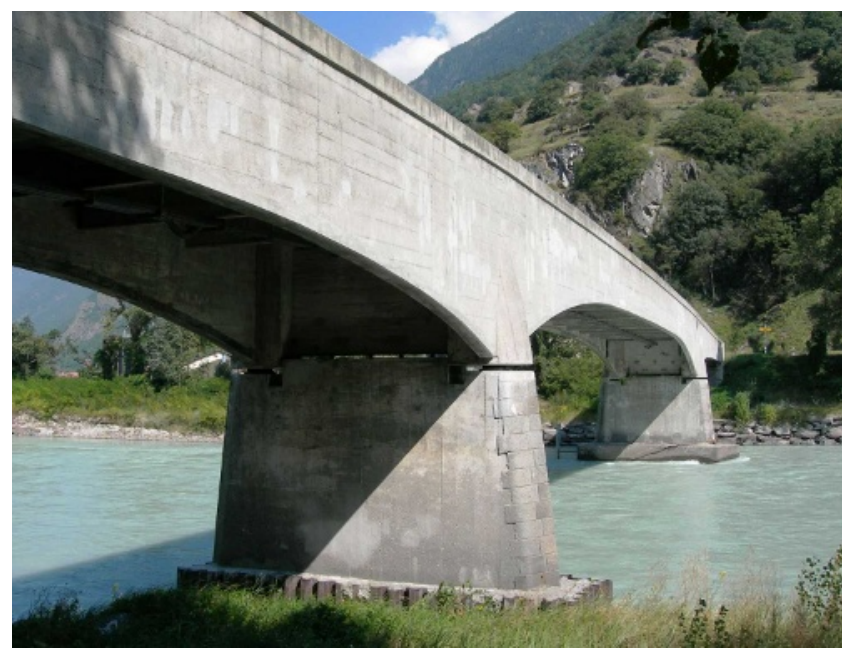

Figure 2. Road bridge over the Rhone at Dorénaz, canton of Valais safety (Bailey et al., 1999). To extend durability, local repairs of steel rebars damaged by corrosion leaving visible marks as age indicators were performed and all concrete surfaces were treated using corrosion inhibitors. This rehabilitation improved the durability and the load-carrying capacity of the bridge, while the original character of the bridge was preserved for a long remaining service life with unrestricted traffic.

\subsection{Gueuroz road bridge}

This structure, with an arch span of 99 m, was built in 1933 and is the most famous bridge designed by Alexandre Sarrasin. It is characterised by its slender and bold concrete structure assembled with linear members that form a light arch and a U-shaped girder that provides structural stiffness. In 1994, a new steel-concrete composite bridge was built parallel to the original bridge to accommodate increasing traffic needs (Figure 3). The concrete bridge structure showed a similar type of damage as found on Dorénaz Bridge and its rehabilitation in 2005 followed the same basic concepts. The concrete bridge can now be used for one-lane traffic during maintenance work on the new bridge.

\subsection{Schwandbach and Rossgraben Bridges}

In 1933, Robert Maillart (1872-1940), the most famous Swiss concrete bridge builder, designed and built two bridges close to one another. Schwandbach Bridge (Figure 4(a)) is a deckstiffened arch that carries a curved roadway. Rossgraben Bridge (Figure 4(b)), with its arch span of $82 \mathrm{~m}$, is the second largest open-box three-hinge arch structure after Maillart's world-famous Salginatobel Bridge. Both RC structures showed satisfactory performance in terms of load-carrying behaviour and durability. Therefore, after more than 70 years of being in service, relatively very little rehabilitation was necessary to restore their durability. Detailed examination of the structures

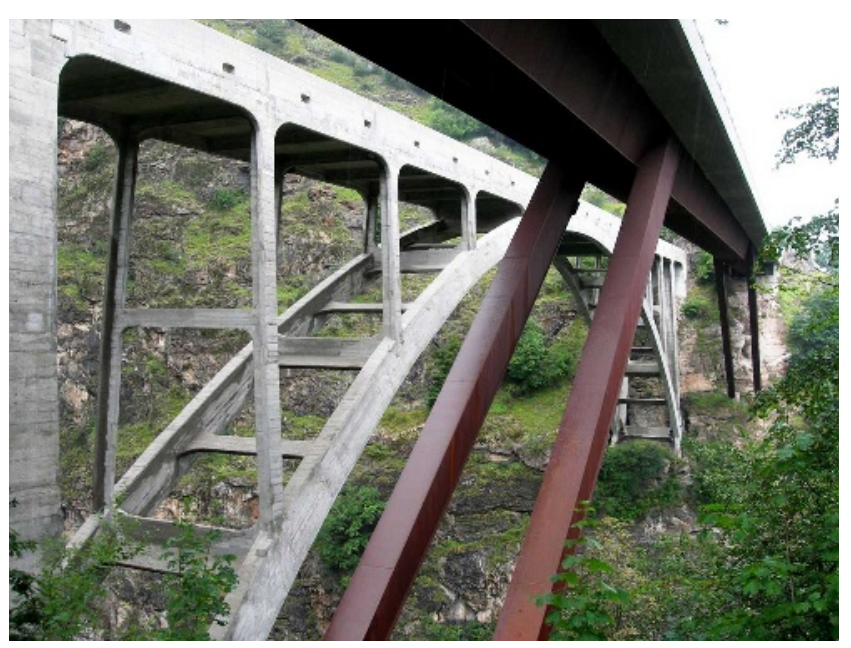

Figure 3. Gueuroz road bridges at Salvan, canton of Valais 


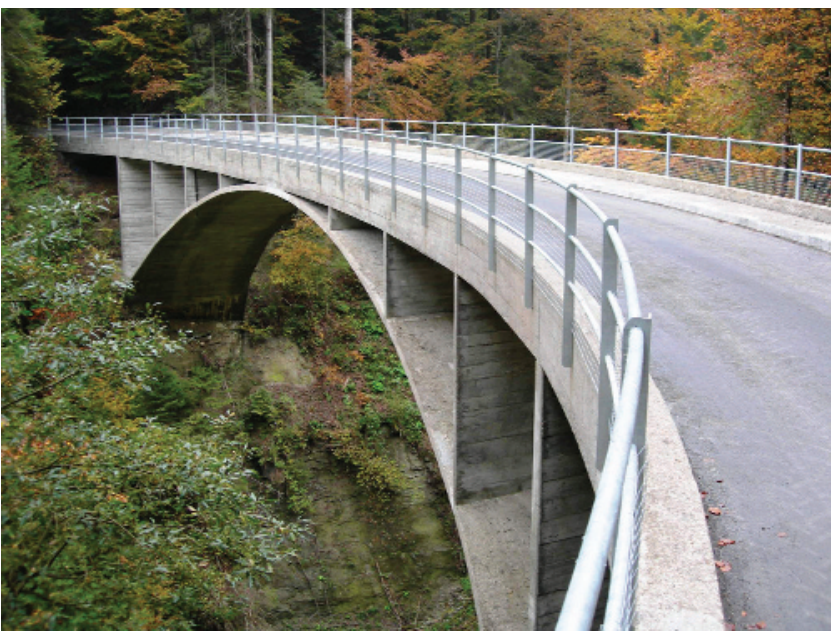

(a)

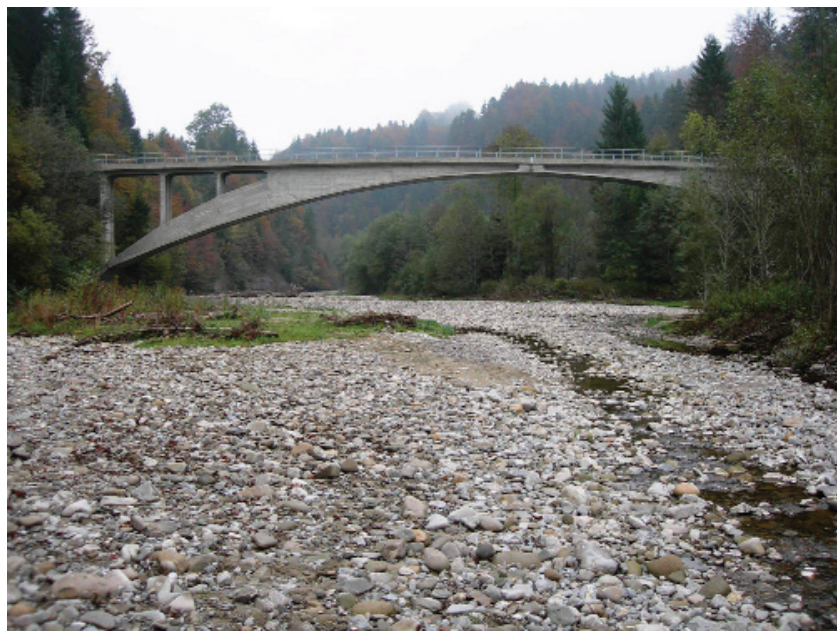

(b)

Figure 4 (a) Schwandbach Bridge and (b) Rossgraben Bridge near Schwarzenburg, canton of Berne

showed that the load-carrying capacity was sufficient for future traffic loads.

Rehabilitation works performed in 2005 comprised

improving the entire water drainage system

placing a waterproofing membrane on the deck slab

- locally repairing zones where steel rebars were damaged by corrosion

- protecting the exposed concrete surfaces with in-depth hydrophobic treatment (i.e. allowing for impregnation of the concrete up to a $20 \mathrm{~mm}$ depth).

This low-impact and cost-effective rehabilitation brought no visible change to the structures yet significantly improved the service life of these very high cultural value bridges.

\subsection{Javroz road bridge}

In 1950, Henri Gicot (1897-1982) designed Javroz Bridge to replace a riveted arch bridge. The design of this rather slender structure is influenced by Sarrasin's arch bridges. The cultural value and aesthetic quality of this bridge are attributed to its integration into the landscape and its elegance and transparency (Figure 5).

Due to a predicted increase in future traffic demand, the bridge had to be widened by more than $3 \mathrm{~m}$. This led to a visible intervention performed in 1999 and 2000. The bridge deck was widened symmetrically by cantilever slabs and strengthened by external post-tensioning. To improve the durability of the bridge, Gerber (halving) expansion joints were removed, which led to a modification of the static system. Furthermore, corrosion damage on the steel rebars was repaired and the entire deck slab was protected with a waterproofing membrane. All works had to be performed while maintaining one lane of traffic (Brühwiler, 2002).

The characterising lines of the bridge are defined by the strong arch and the kerb. Therefore, dimensioning and detailing of the kerb of the widened deck slab were carefully carried out to obtain (optical) equilibrium with the strong arch. The aesthetic appearance of the structure was thus slightly improved.

\subsection{Schwarzwasser Bridge}

The deck of this road bridge, built in 1882, had to be replaced and widened in 2005 to respond to the requirements of future traffic needs. With an arch span of $112 \mathrm{~m}$, this bridge is one of the most impressive nineteenth century riveted bridges in Switzerland (Figure 6). It was designed by the Swiss steel bridge engineer Beat Gubser (1836-1882) and built by the steel construction company G. Ott \& Cie from Berne. The bold appearance and elegance of the structure, as well as its

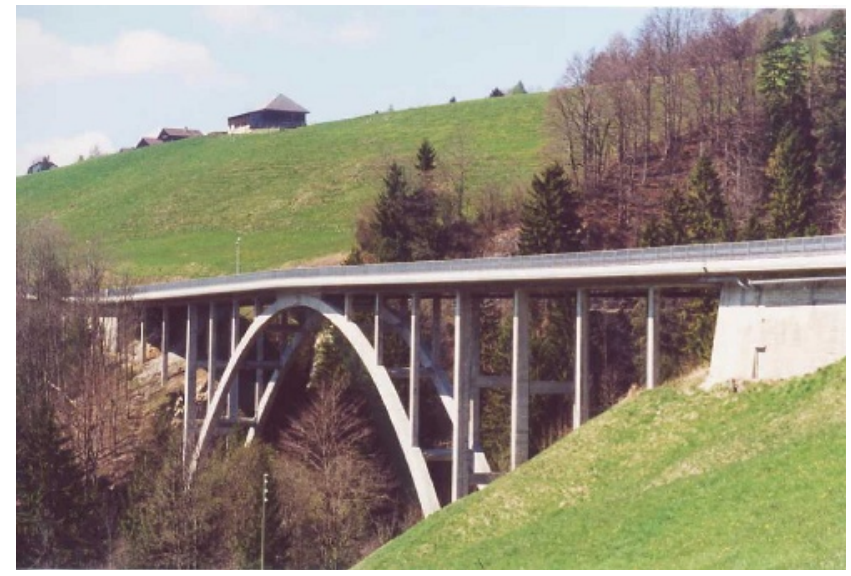

Figure 5. Javroz road bridge at Charmey, canton of Fribourg 


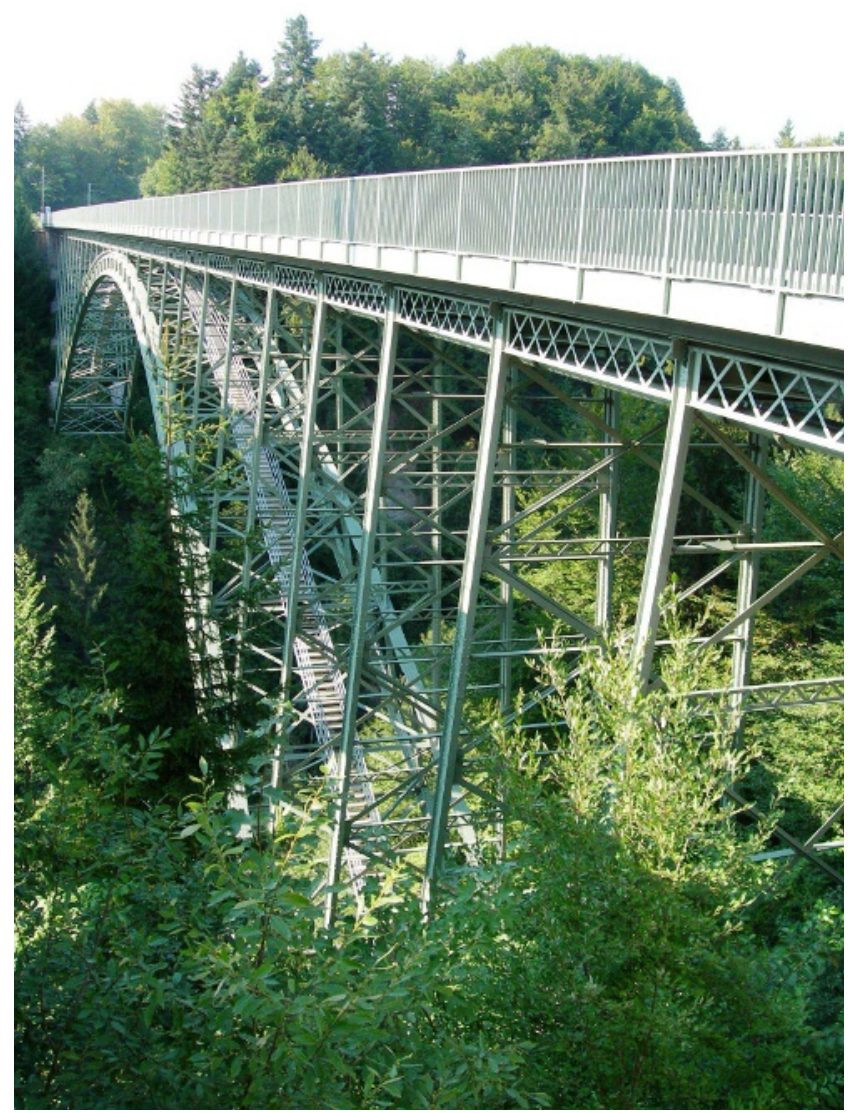

Figure 6. Schwarzwasser Bridge near Schwarzenburg, canton of Berne

importance for steel construction in Switzerland, justify its high cultural value.

To accommodate a wider traffic surface, the concrete deck slab had to be replaced by wider prefabricated elements. Detailed examination of the riveted wrought-iron structure showed an almost sufficient load-carrying capacity for future higher traffic loads. Only minor strengthening of the arch had to be performed to improve structural capacity. The original character of the bridge was preserved, it was adapted to cater for future traffic needs and its service life was largely extended. The prefabricated deck elements allowed for a rapid construction process and traffic restrictions during the works were thus very limited. The intervention cost was significantly lower than the estimated cost of bridge replacement.

\subsection{Bessières Bridge}

Bessières Bridge, located next to the old town of Lausanne, was designed by the well-known railway engineer Jules Gaudard (1833-1917) with detailing by the architect Eugène Jost (18651946) and built in 1910 by the 'Atelier de construction mécanique' in Vevey (Figure 7). With a span of $81 \mathrm{~m}$, the bridge consists of five steel arches resting on massive natural stone masonry piers. Rehabilitation works were performed in 2003. The rehabilitation project involved

- repair of corrosion-damaged steel rebars in the RC deck slab

replacement of the waterproofing membrane on the top surface of the deck

renewal of the corrosion-protective coating on the steel structure

redesign and installation of new and higher bridge railings (Brühwiler and Guex, 2003).

Special attention was paid to the choice of colours and structural details in order to respect the bridge's original character. The bridge, with the Cathedral in the background, provides a postcard view of the old city of Lausanne. In 2006, a new bridge for the Lausanne Metro line was built underneath the arch bridge. This bridge follows the axis of Bessières Bridge and crosses through its masonry piers - an original urban 'bridge landscape' was created!

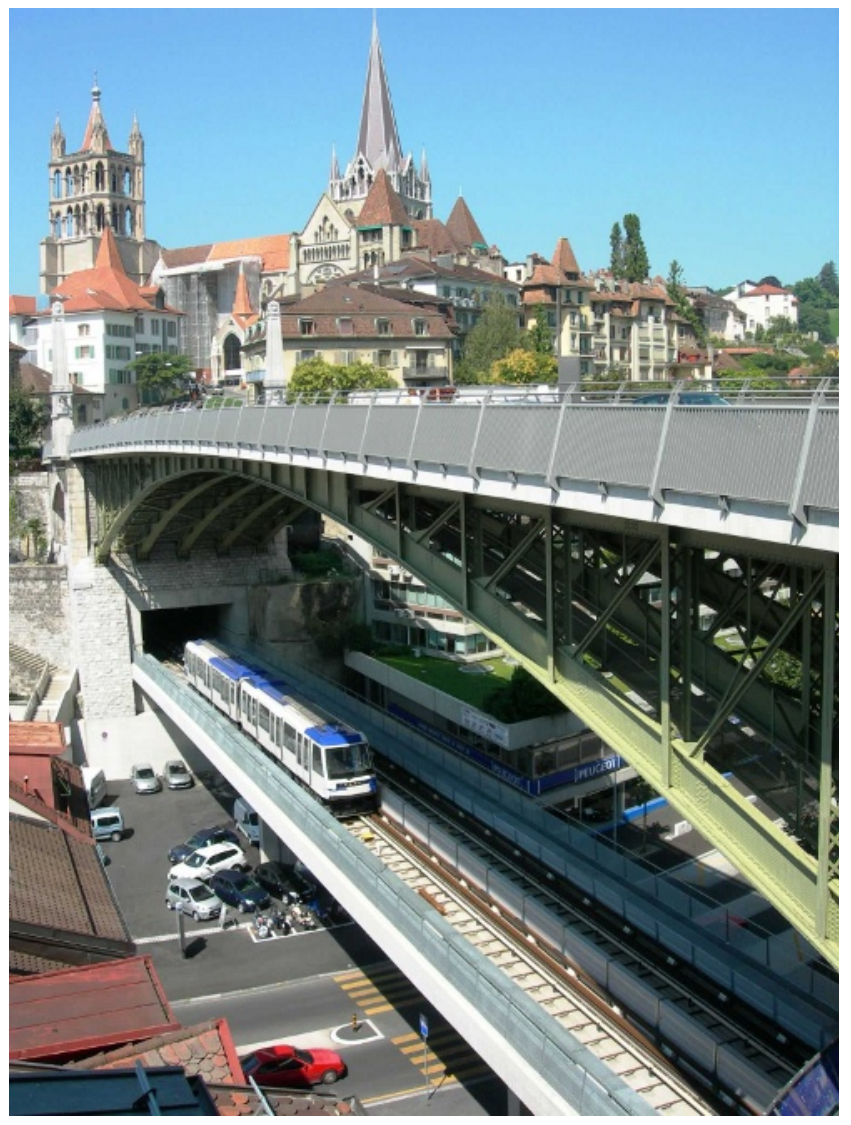

Figure 7. Bessières Bridge in Lausanne, canton of Vaud 


\section{Conclusions}

Construction interventions on bridges of high cultural value must meet stringent utilisation requirements in tandem with their cultural value and aesthetic quality. The examples presented in this paper highlight that most bridges have a certain cultural value that needs to be recognised and respected. There are still many 'undiscovered' and 'ignored' bridges built over the last 60 years, which deserve similar treatment to those presented here. Structural engineers and bridge owners need to be more aware of these aspects when conducting rehabilitation or modification interventions.

Structural engineering with the ultimate goal of limiting construction intervention to a strict minimum is intertwined with the interest of preserving monuments and limiting costs to bridge owners. There are no 'old' bridges - there are bridges that provide adequate performance and those that do not. Extending the service life of bridges by following the approaches presented in this paper will allow continuous utilisation of existing structures rather than their replacement. This approach is clearly in agreement with the principles of sustainable development. Finally, extending service life means not only giving value to the bridges themselves, but also appreciating the identity of the engineers and the art of structural engineering.

\section{REFERENCES}

Bailey SF, Radojicic A and Brühwiler E (1999) Structural safety assessment of the Dorénaz Bridge. In Case Studies in Optimal Design and Maintenance Planning of Civil Infrastructure Systems. American Society of Civil Engineers, Reston, VA, USA, pp. 1-12.

Brühwiler E (2002) The Javroz Bridge - Deck Enlargement and Rehabilitation. fib, Lausanne, Switzerland, pp. 170-172.

Brühwiler E and Frey P (eds) (2002) Alexandre Sarrasin Structures en Béton Armé: Audace \& Invention. Presse polytechnique et universitaire romandes (PPUR), Ecole Polytechnique Fédérale de Lausanne (EPFL), Lausanne, Switzerland.

Brühwiler $\mathrm{E}$ and Guex $\mathrm{P}$ (2003) Remise en état du pont Bessières à Lausanne. Tracés, Bulletin technique de la Suisse Romande 129(21): 7-13.

Brühwiler E and Hirt MA (2010) Umgang mit genieteten Bahnbrücken, Stahlbau 79. Ernst \& Sohn, Berlin, Germany, pp. 209-219.

Brühwiler E, Vogel T, Lang T and Lüchinger P (2012) Swiss standards for existing structures. Structural Engineering International 22(2): 275-280.

Habel K and Brühwiler E (2009) Alexandre Sarrasin - boldness and innovation in concrete design. ACI Concrete International 104(1): 47-52.

Keller A, Brühwiler E and Hirt MA (1995) Assessment of a 135 year old riveted railway bridge. Proceedings of IABSE Symposium, San Francisco, CA, USA. International Association for Bridge and Structural Engineering, Zurich, Switzerland, Report 73/2, pp. 1029-1034.

\section{WHAT DO YOU THINK?}

To discuss this paper, please email up to 500 words to the editor at journals@ice.org.uk. Your contribution will be forwarded to the author(s) for a reply and, if considered appropriate by the editorial panel, will be published as discussion in a future issue of the journal.

Proceedings journals rely entirely on contributions sent in by civil engineering professionals, academics and students. Papers should be 2000-5000 words long (briefing papers should be 1000-2000 words long), with adequate illustrations and references. You can submit your paper online via www.icevirtuallibrary.com/content/journals, where you will also find detailed author guidelines. 